\title{
Metabolic syndrome, obstructive sleep apnea, and risk of cardiovascular disease
}

\author{
James M. Parish
}

Received: 12 August 2011 /Revised: 22 August 2011 /Accepted: 5 September 2011 / Published online: 11 October 2011

(C) Springer-Verlag 2011

This editorial published in the same issue as the paper by Roche et al., "Obstructive sleep apnea and the metabolic syndrome in an elderly healthy population: the SYNAPSE cohort" is relevant to the knowledge about the adverse health consequences of obstructive sleep apnea and other abnormalities of sleep which continue to grow rapidly. In view of the expanding prevalence of obesity in the population, continued research in this area is very important. Obesity, especially central obesity, is strongly associated with obstructive sleep apnea (OSA) [1]. Both obesity and OSA are known risk factors for cardiovascular disease based on evidence documented by large epidemiological studies such as the Sleep Heart Health study [2], the Wisconsin Sleep Cohort study [3], and many other excellent studies [4-6]. OSA is also a major risk factor for atrial fibrillation and stroke even after taking obesity and other traditional risk factors into account $[7,8]$.

Obesity is also a central component of the metabolic syndrome (MS), a grouping of metabolic abnormalities including insulin resistance, hypertriglyceridemia, low HDL cholesterol, and hypertension which are important risk factors for subsequent cardiovascular disease. Insulin resistance is, of course, associated with diabetes, which in turn is a substantial risk factor for atherosclerosis and cardiovascular disease. Some investigators believe that OSA should be grouped into the definition of MS since it occurs so frequently in association with the other parameters of the syndrome [9]. A recent meta-analysis found that MS is an independent risk factor for cardiovascular disease

J. M. Parish ( $\square)$

Division of Pulmonary Medicine, Center for Sleep Medicine,

Mayo Clinic,

13400 East Shea Boulevard,

Scottsdale, AZ 85259, USA

e-mail: parish.james@mayo.edu
[10], and the relationship and interaction of OSA in the context of obesity, diabetes, and MS has been an active area of investigation. For example, in a recent study, Trombetta et al. examined patients with MS plus OSA compared to a group with MS but without OSA and found those with comorbid MS and OSA had higher blood pressure, higher sympathetic nervous system drive, and abnormal baroreflex sensitivity which is correlated with abnormal autonomic nervous system activity. High blood pressure, high sympathetic drive, and abnormal baroreflex sensitivity have been implicated in the pathogenesis of cardiovascular disease. In multivariate analysis, the changes of abnormal sympathetic nervous system activity were more strongly associated with OSA than obesity and diabetes [11].

Several lines of investigation have shed light on strong and interesting relationships of sleep abnormalities and metabolic abnormalities. Over the past decade, investigators have discovered a relationship of OSA with hyperglycemia and insulin resistance $[12,13]$ [14] even independent of the presence of obesity. Additional research has documented that short sleep duration is associated with insulin resistance [15]. The study of short sleep duration is important for a variety of reasons, one of which is that it may serve as a model of the frequent arousals and disrupted sleep associated with OSA. Subjects with short sleep are heavier and have preference for foods higher in carbohydrates and fats compared with normal sleepers [16]. Even 1 week or even one night of short sleep (defined as less than $6 \mathrm{~h}$ ) is associated with the finding of insulin resistance [17, 18]. Short sleep duration and obstructive sleep apnea both appear to be associated with increase in body mass index [19]. Short sleep time is associated with increased cortisol levels, increased sympathetic nervous activity, reduced glucose tolerance, increased blood pressure, reduced leptin (a hormone that suppresses appetite), increased grehlin (a hormone that acts in an 
opposite manner of leptin and increases appetite), and increase in inflammatory markers primarily C-reactive protein, a marker associated with cardiovascular disease [20]. Self-reported short sleep duration is associated with a $45 \%$ increase in risk of having MS and is independently associated with abdominal obesity, elevated fasting glucose, and hypertriglyceridemia [21]. Another study found that a diabetic patient with untreated OSA is more likely to have poorer glucose control and more frequent complications compared to a patient without OSA [22].

In this paper, the authors investigate the relationship of OSA and MS in a cohort of healthy older individuals. Previous studies examining this relationship of OSA and MS have looked at primarily middle-aged groups, while this study focuses on a large group of community dwelling individuals. This study is part of a larger prospective cohort study, the PROOF study, examining cardiovascular risk factors in a group of community-dwelling individuals in France. Strengths of this study include the large sample size $(n=806)$, the comprehensive evaluation of general health, metabolic measurements including glucose and lipid measurements, and sleep studies in all. The mean age of the study group was 68 years. OSA was found in 449 (55.9\%), the prevalence of MS was 9.8\%. Previous epidemiologic studies have estimated the prevalence of MS of $22 \%$ in the general population. The subjects with $\mathrm{MS}$ in this group have a BMI greater than the control group (29.7 vs 25) supporting that increased body weight is a fundamental characteristic of MS. These data are especially important in the finding that about $10 \%$ of otherwise healthy elderly of modest body weight have MS and over 55\% have significant OSA. These findings have significant ramifications for the overall burden of cardiovascular disease in this group. The expected associations were found: MS was correlated with increased neck circumference, hip circumference, and other markers of obesity. MS was strongly associated with higher levels of fasting glucose and triglycerides, lower levels of HDL cholesterol, and hypertension, which is not surprising as these are the elements which make up the definition of MS. A significant finding in this study is the increased severity of sleep-disordered breathing in subjects with MS: mean apnea-hypopnea index (AHI) was 26.3 in those with MS compared with 19.7 in those without MS. The importance of intermittent hypoxia in pathogenesis of adverse effects of OSA is supported here by the finding that the oxygen desaturation index is more closely correlated with MS than is the AHI.

This study is important because it adds additional information to our understanding of the risk of cardiovascular disease, MS, and OSA. Further information from this ongoing prospective cohort study is eagerly anticipated as it will enlighten us further in this important area. Further areas of investigation will be to define which variables of the metabolic syndrome and OSA are most predictive of cardiovascular disease, which pathophysiological mechanisms are important, and the effects of treating OSA on altering its adverse consequences. With the high prevalence of obesity, MS, and OSA in the population, answering these questions will have very important ramifications.

Conflict of interest The author has no conflict of interest to disclose.

\section{Reference}

1. Pillar G, Shehadeh N (2008) Abdominal fat and sleep apnea: the chicken of the egg? Diabetes Care 31:S303-S309

2. Nieto FJ, Young TB, Lind BK, Shahar E, Samet JM, Redline S, D'Agostino RB, Newman AB, Lebowitz MD, Pickering TG (2000) Association of sleep-disordered breathing, sleep apnea, and hypertension in a large community-based study. Sleep Heart Health Study. JAMA 283:1829-1836

3. Peppard PE, Young T, Palta M, Skatrud J (2000) Prospective study of the association between sleep-disordered breathing and hypertension. New Engl J Med 342:1378-1384

4. Parish JM, Somers VK (2004) Obstructive sleep apnea and cardiovascular disease. Mayo Clin Proc 79:1036-1046

5. Shamsuzzaman ASM, Gersh BJ, Somers VK (2003) Obstructive sleep apnea: implications for cardiac and vascular disease. JAMA 290:1906-1914

6. Somers VK, White DP, Amin R, Abraham WT, Costa F, Culebras A, Daniels S, Floras JS, Hunt CE, Olson LJ, Pickering TG, Russell R, Woo M, Young T (2008) Sleep apnea and cardiovascular disease: an American Heart Association/American College of Cardiology Foundation Scientific Statement from the American Heart Association Council for High Blood Pressure Research Professional Education Committee, Council on Clinical Cardiology, Stroke Council, and Council on Cardiovascular Nursing in collaboration with the National Heart, Lung, and Blood Institute National Center on Sleep Disorders Research (National Institutes of Health). J Am Coll Cardiol 52:686-717

7. Gami AS, Pressman G, Caples SM, Kanagala R, Gard JJ, Davison DE, Malouf JF, Ammash NM, Friedman PA, Somers VK (2004) Association of atrial fibrillation and obstructive sleep apnea. Circulation 110:364-367

8. Yaggi HK, Concato J, Kernan WN, Lichtman JH, Brass LM, Mohsenin V (2005) Obstructive sleep apnea as a risk factor for stroke and death. N Engl J Med 353:2034-2041

9. Vgontzas AN, Bixler EO, Chrousos GP (2005) Sleep apnea is a manifestation of the metabolic syndrome. Sleep Med Rev 9:211-224

10. Gami AS, Witt BJ, Howard DE, Erwin PJ, Gami LA, Somers VK, Montori VM (2007) Metabolic syndrome and risk of incident cardiovascular events and death: a systematic review and metaanalysis of longitudinal studies. J Am Coll Cardiol 49:403-414

11. Trombetta IC, Somers VK, Maki-Nunes C, Drager LF, ToschiDias E, Alves MJ, Fraga RF, Rondon MU, Bechara MG, LorenziFilho G, Negrao CE (2010) Consequences of comorbid sleep apnea in the metabolic syndrome - implications for cardiovascular risk. Sleep 33:1193-1199

12. Ip MS, Lam B, Ng MM, Lam WK, Tsang KW, Lam KS (2002) Obstructive sleep apnea is independently associated with insulin resistance. Am J Respir Crit Care Med 165:670-676 [see comment] 
13. Punjabi NM, Shahar E, Redline S, Gottlieb DJ, Givelber R, Resnick HE (2004) Sleep-disordered breathing, glucose intolerance, and insulin resistance: The Sleep Heart Health Study. Am J Epidemiol 160:521-530

14. Gottlieb DJ, Punjabi NM, Newman AB, Resnick HE, Redline S, Baldwin CM, Nieto FJ (2005) Association of sleep time with diabetes mellitus and impaired glucose tolerance. Arch Intern Med 165:863-867

15. Rafalson L, Donahue RP, Stranges S, Lamonte MJ, Dmochowski J, Dorn J, Trevisan M (2010) Short sleep duration is associated with the development of impaired fasting glucose: The Western New York Health Study. Ann Epidemiol 20(12):883-889

16. Spiegel K, Tasali E, Penev P, Cauter EV (2004) Brief communication: sleep curtailment in healthy young men is associated with decreased leptin levels, elevated ghrelin levels, and increased hunger and appetite. Ann Intern Med 141:846-850

17. Buxton OM, Pavlova M, Reid EW, Wang W, Simonson DC, Adler GK (2010) Sleep restriction for 1 week reduces insulin sensitivity in healthy men. Diabetes 59:2126-2133
18. Donga E, van Dijk M, van Dijk JG, Biermasz NR, Lammers G-J, van Kralingen KW, Corssmit EPM, Romijn JA (2010) A single night of partial sleep deprivation induces insulin resistance in multiple metabolic pathways in healthy subjects. J Clin Endocrinol Metab 95:2963-2968

19. Taheri S, Lin L, Austin D, Young T, Mignot E (2004) Short sleep duration is associated with reduced leptin, elevated ghrelin, and increased body mass index. PLoS Med 1:e62

20. Mullington JM, Haack M, Toth M, Serrador JM, Meier-Ewert HK (2009) Cardiovascular, inflammatory, and metabolic consequences of sleep deprivation. Prog Cardiovasc Dis 51: 294-302

21. Hall MH, Muldoon MF, Jennings JR, Buysse DJ, Flory JD, Manuck SB (2008) Self-reported sleep duration is associated with the metabolic syndrome in midlife adults. Sleep 31:635-643

22. Aronsohn RS, Whitmore H, Van Cauter E, Tasali E (2010) Impact of untreated obstructive sleep apnea on glucose control in type 2 diabetes. Am J Respir Crit Care Med 181: $507-513$ 